\title{
Evaluation of patient safety culture among Malaysian retail pharmacists: results of a self-reported survey
}

This article was published in the following Dove Press journal:

Patient Preference and Adherence

25 July 2016

Number of times this article has been viewed

\author{
Palanisamy Sivanandy' \\ Mari Kannan Maharajan' \\ Kingston Rajiah' \\ Tan Tyng Wei ${ }^{2}$ \\ Tan Wee Loon ${ }^{2}$ \\ Lim Chong $\mathrm{Yee}^{2}$ \\ 'Department of Pharmacy Practice, \\ School of Pharmacy, ${ }^{2}$ School of \\ Pharmacy, International Medical \\ University, Wilayah Persekutuan Kuala \\ Lumpur, Malaysia
}

Background: Patient safety is a major public health issue, and the knowledge, skills, and experience of health professionals are very much essential for improving patient safety. Patient safety and medication error are very much associated. Pharmacists play a significant role in patient safety. The function of pharmacists in the medication use process is very different from medical and nursing colleagues. Medication dispensing accuracy is a vital element to ensure the safety and quality of medication use.

Objective: To evaluate the attitude and perception of the pharmacist toward patient safety in retail pharmacies setup in Malaysia.

Methods: A Pharmacy Survey on Patient Safety Culture questionnaire was used to assess patient safety culture, developed by the Agency for Healthcare Research and Quality, and the convenience sampling method was adopted.

Results: The overall positive response rate ranged from $31.20 \%$ to $87.43 \%$, and the average positive response rate was found to be $67 \%$. Among all the eleven domains pertaining to patient safety culture, the scores of "staff training and skills" were less. Communication openness, and patient counseling are common, but not practiced regularly in the Malaysian retail pharmacy setup compared with those in USA. The overall perception of patient safety of an acceptable level in the current retail pharmacy setup.

Conclusion: The study revealed that staff training, skills, communication in patient counseling, and communication across shifts and about mistakes are less in current retail pharmacy setup. The overall perception of patient safety should be improved by educating the pharmacists about the significance and essential of patient safety.

Keywords: patient counseling, medication errors, communication openness, perceptions, attitudes

\section{Introduction}

The future of human well-being depends on our ability to deal with advanced health care services. Accumulating evidence advocates that a number of patients are affected by health care services such as health care-associated infections, diagnostic errors, and medication errors. Patient safety is the ultimate principle for health care providers to achieve high-quality health care. However, it is a major public health issue, affecting countries worldwide at all levels of development. ${ }^{1}$ The knowledge, skills, and experience of health care professionals are essential for improving patient safety and to achieve quality of care. ${ }^{2}$ Globally, medical error and adverse event reporting are becoming major issues in health care systems. Absence of a well-developed system to manage medical error in developing countries has increased the uncertainty. Over
Correspondence: Palanisamy Sivanandy Department of Pharmacy Practice, School of Pharmacy, International Medical University, No 126, Jalan Jalil Perkasa 19, Bukit Jalil, 57000 Kuala Lumpur, Malaysia

Tel +60327317573

Email palanisamysivanandy@imu.edu.my 
the past few years, increased medication errors have led to elevated risk of patient harm. ${ }^{3}$

It is a fundamental principle of health care professionals to ensure patient safety during their practice. While all health care practitioners share professional responsibility to ensure patient safety, being alert to drug-related problems and steering preventive pharmaceutical interventions to maintain patient safety are of major concern to pharmacists. For centuries, pharmacists have been the guardians against "drugs that are also known as poisons", which could cause harm to the patient or public. A considerable variation in perceptions of safety culture across organizations has been documented. ${ }^{4}$

In developing countries, the right for drug prescription is entitled only to medical practitioners. However, pharmacists play a significant role in prescription screening. ${ }^{4}$ Prescription screening minimizes risk of medication error while increasing patient safety. Nevertheless, errors can be made during prescription screening also. For instance, pharmacists may feel rushed when screening through prescriptions during peak hours or important prescription information may not be exchanged across shifts. Hence, these may increase the risk of medication or even dispensing error, leading to patient harm. ${ }^{4}$ The retail pharmacists play a significant role in providing patient safety as they not only involve in checking and filling prescriptions from the doctors, but they also participate in communicating with patients, managing inventories, and maintaining documents. ${ }^{5}$ In a retail pharmacy setup without proper implementation of patient safety culture, the pharmacists are easily short-handed, make improper decisions, and increase the probability of error.

The training, role, and function of community pharmacists in the medication use process are very different from medical and nursing colleagues, which may mean that their attitudes toward errors and reporting behavior are different. A strong evidence base does not yet exist about how patient safety culture is understood and applied during practice. ${ }^{6-9}$

"Patient safety culture" may be described as the common values, beliefs, behaviors, perceptions, and attitudes of the staff in a health care center. ${ }^{10}$ Community health care units need an "organizational safety culture" similar to that established in hospitals. ${ }^{11}$ Improving patient safety culture should be a priority among health center administrators. Health care staff should be encouraged to report errors without fear of punitive action. ${ }^{12}$ The generation of a safety culture starts with an evaluation of the present safety level in a health care because safety precautions implemented without a proper assessment may elevate costs and also cause unpredicted new risks. ${ }^{13}$ Many tools have been developed for evaluation of patient safety culture. ${ }^{14,15}$ Nearly all these tools cover five common dimensions of patient safety climate: leadership, policies and procedures, staffing, communication, and reporting. ${ }^{16}$ Patient safety culture is a relatively new area, ${ }^{13}$ and published studies in this field are based on hospitals..$^{13,15-17}$ There is a need to improve current understanding of the organizational and individual variables and mechanisms responsible for patient outcomes in community settings. The safety of medicinal products and the consumer (patient) in retail pharmacy setup is a very important area to be focused. There are several studies that analyzed patient safety culture in a hospital setup..$^{11,12,14,15,17}$ However, there is no study on patient safety culture in community pharmacy settings and none has focused on a retail pharmacy setup in Malaysia. Therefore, the aim of this study was to explore the attitude and perception of retail pharmacists toward patient safety and to identify the strength and areas for patient safety improvement.

\section{Methods \\ Study setup}

Malaysian retail pharmacies are recognized by standardizing with community pharmacy benchmarking guidelines of Malaysia. A retail pharmacy in Malaysia should comply with Malaysian government policies and legislations. The retail pharmacist working in a pharmacy has full management control of the pharmacy. Pharmacists in Malaysia are primary providers of medications to the public and their significant role in dispensing and counseling is well suited to promote effective use of medications and patient safety. ${ }^{18}$ Malaysian Adverse Drug Reactions Advisory Committee (MADRAC) was established under the Drug Control Authority to perform the function of pharmacovigilance for drugs registered for use in Malaysia, which ancillarily supports in patient safety. ${ }^{19}$

\section{Study design and target population}

A cross-sectional study on article-based noninterventional survey was carried out in three selected states of Malaysia, for a period of 6 months from May to October 2015. The targeted population was the pharmacists who are working in retail pharmacies. Any retail pharmacists from the three states (Selangor, Johor, and Melaka) in Malaysia were selected based upon the accessibility of the researchers. As per the information obtained from the Principal Assistant Director, Pharmacy Board of Malaysia, the number of retail pharmacists available in three states is as follows: Selangor, 550; Johor, 217; and Melaka, 61. All registered pharmacists, regardless of working daily shifts in retail pharmacies and ready to participate in this survey, were included. Those who were not willing to participate or those who cannot read English were excluded from this study. 


\section{Sampling and sample size}

In each of those three states, stratified sampling method was used to recruit the samples. The sample size of each state was calculated by using a formula for estimation of population proportion. A total of $10 \%$ of the calculated sample size was added to compensate the nonresponse rate. Sample sizes of the three states were calculated as Selangor, 227; Johor, 136; and Melaka, 54.

\section{Study instrument}

This survey emphasizes on patient and medication safety and quality assurance issues. The Pharmacy Survey on Patient Safety Culture (PSOPSC) questionnaire was adapted from an earlier study. ${ }^{20}$ The self-administered questionnaire consists of 36 items, which were segregated into eleven different domains. $^{20}$

\section{Reliability of questionnaire}

The consistency and reliability of the questionnaire were measured using internal consistency based on Cronbach's $\alpha{ }^{21}$ The overall internal consistency of this study was excellent with Cronbach's $\alpha$ of $0.920 .{ }^{22}$ Moreover, this study demonstrated that Cronbach's $\alpha$ ranged from 0.748 to 0.861 for eleven dimensions. This indicates that the internal consistency was good for all eleven dimensions $(\alpha>0.7){ }^{23}$

\section{Data collection procedure}

The survey questionnaire along with study information sheet and consent form were distributed and sufficient time was given for the participants to complete the questionnaire. Additionally, two reminders were given; the first reminder after the first week and the second after the second week by telephonic call. The responses were collected on the third week and analyzed for its appropriateness. The number of years the pharmacists worked in retail pharmacy has been counted as their work experience. Respondents with a work experience of 1 year or more were categorized as senior pharmacists, whereas those with working experience of $<1$ year were categorized as junior pharmacists. ${ }^{23}$

\section{Data analysis}

Positive response rate calculation ${ }^{22}$

A positive response rate (PRR) ${ }^{22}$ was used to evaluate the attitudes toward patient safety culture on different dimensions. The PRR was calculated by the formula mentioned in the user's guide of PSOPSC. The results were aggregated considering the agreement indices given in the PSOPSC guide. Most of the items in the questionnaire used the Likert five-point response scale of agreement (strongly disagree to strongly agree), in which "strongly disagree" scores 1 point and "strongly agree" scores 5 points. Some of the items in the questionnaire used the scale of frequency (never to always), in which "never" scores 1 point and "always" scores 5 points. The highest two scores ( 4 and 5 points) were perceived to be "positive response", while the lowest three scores $(1,2$, and 3 points) were perceived to be "other response". In order to find out the differences in attitude between senior and junior pharmacists, the results were compared using the number of positive responses and a number of other responses.

The collected data were analyzed using the Statistical Package for Social Sciences (SPSS Inc., Chicago, IL, USA) Version 18.0. A $\chi^{2}$ test was used to compare whether there was a statistical difference between perception of pharmacists toward patient safety and their work experience. "Patient safety grade" in retail pharmacies was assessed by asking the pharmacists to rate their pharmacy as "poor", "bad", "good", "very good", and "excellent".

\section{Ethical approval}

This study was approved by the International Medical University Joint-Committee on Research and Ethics (BP-I01/12(54)/2015). All participants signed the written informed consent form.

\section{Results}

A total of 417 pharmacists from the three states were approached to participate in this study. A total of 390 participants (Selangor, 210; Johor, 131; and Melaka, 49) completed the questionnaire, and the response rate was $93.52 \%$. More than $70 \%$ of the respondents were junior pharmacists. The

Table I Sociodemographic characteristics of the respondents $(n=390)$

\begin{tabular}{llll}
\hline Characteristics & $\begin{array}{l}\text { Senior } \\
\text { pharmacist (n) }\end{array}$ & $\begin{array}{l}\text { Junior } \\
\text { pharmacist (n) }\end{array}$ & Total (n) \\
\hline $\begin{array}{llll}\text { Sex } \\
\text { Male }\end{array}$ & 43 & 59 & 102 \\
Female & 71 & 217 & 288 \\
Work experience in pharmacy & 0 & 132 & 132 \\
$<6$ months & 0 & 144 & 144 \\
6 months to $<$ I year & 43 & 0 & 43 \\
I year to $<3$ years & 43 & 0 & 48 \\
3 years to $<6$ years & 48 & 0 & 18 \\
6 years to $<12$ years & 18 & 0 & 5 \\
$\geq 12$ years & 5 & & 10 \\
Working hours per week & 0 & 10 & 26 \\
I-I6 & 5 & 21 & 133 \\
I7-3I & 33 & 100 & 221 \\
$32-40$ & 76 & 145 & \\
$>40$ & & &
\end{tabular}


majority of the senior pharmacists had 3-6 years of work experience $(n=48 ; 12.31 \%)$, whereas, among the junior pharmacists most of the respondents had 6 months of work experience ( $n=144 ; 36.92 \%)$. Irrespective of their work experience, the working hours per week for most of the senior and junior pharmacists were observed to be $>40$ hours $(76$ senior and 145 junior pharmacists). Among the respondents, there were no senior pharmacists working for 1-16 hours in a week. However, at least ten junior pharmacists were found to work for 1-16 hours in a week. The detailed data is represented in Table 1.

The perception of pharmacists about patient safety is important to achieve patient safety in the pharmacy setup. Therefore, this study focused more on PRR calculation as it could provide a big picture of the perception of pharmacists on various domains, such as environment, teamwork, skills, staff report, and patient counseling. The responses of all pharmacists from three states were recorded. The PRR calculation revealed that "Teamwork" domain scored the highest PRR and it was 80.98. "Patient counseling" domain scored the second highest PRR of 78.67. Third highest value was the "Staff training and skills" domain with 77.63. However, domains such as "Communication about prescription across shifts", "Responses to mistakes", and "Overall perceptions of patient safety" scored low PRR of 60.81, 60.05, and 51.75, respectively. Among all domains, "Staffing, work pressure and pace" scored a very low PRR of 46.18. An overall PRR of 67 was observed for all 36 items. Table 2 shows the detailed scores.

The comparative study revealed that the relative frequency or occurrence of patient safety issues was closely related to the work experience of the pharmacist. There was a significant difference between items mentioned in the questionnaire and work experience of pharmacists. Those seven items were "Staff ideas and suggestions are valued in this pharmacy", "Staff work together as an effective team", "Staffs treat each other with respect", "We have enough staff to handle the workload", "When patient safety issues occur in this pharmacy, staff discuss them", "Staff are treated fairly when they make mistakes", and "When a mistake happens, we try to figure out what problems in the work process led to the mistake". The data are presented in Table 3.

The overall patient safety grade for pharmacy was assessed by their own rating. The majority of the junior pharmacists rated their pharmacy as "good" in patient safety, whereas most of the senior pharmacists rated their pharmacy as "very good" in patient safety. Very few pharmacists (both senior and junior, $1.03 \%$ ) rated their pharmacy as "poor" in patient safety. The detailed information are depicted in Table 4.

\section{Discussion}

The results of the study may not entirely reflect the actual scenario in retail pharmacies. The questionnaire may not be attempted diligently, unless the Ministry of Health authorizes compulsory attempt of this survey. The response biases may exist because negative responses may affect the reputation of their pharmacies; hence, there might be a slight tendency to fill in more positive or neutral responses. In addition, the sample size may not be large enough to obtain a reliable and consistent result.

Above all, the study explored patient safety culture in the community pharmacy using the PSOPSC. The results of this study provided information on the strength and areas of concern for the community pharmacists in their patient safety culture. ${ }^{24}$ The high response rate on a questionnaire reflects the attitude of community pharmacists in Malaysia toward patient safety-related issues. ${ }^{25}$ The overall mean PRR for patient safety culture was $67 \%$ based on the PSOPSC scale, which is higher than that in earlier studies conducted in Taiwan and the People's Republic of China. ${ }^{26,27}$ The result suggested that the Malaysian pharmacists understood the importance of upholding the values of patient safety in community pharmacy practice. There is an intensive effort by the Malaysian National Patient Safety Council to ensure that all the health care professionals take necessary measures to give patient safety a top priority.

The results also showed that there was significant variability in the percentage of positive scores across dimensions. The highest PRR of a dimension was that of "Teamwork" $(80.98 \%)$, which is similar to that in the studies reported from Belgium, ${ }^{28}$ Turkey, ${ }^{29}$ Sweden, ${ }^{30}$ the USA, ${ }^{31}$ People's Republic of China, ${ }^{32}$ and Taiwan. ${ }^{26}$ The results suggested that teamwork in the workplace among pharmacists was high. The preference for teamwork in Malaysia is stronger and their positive attitude toward teamwork was reported earlier by Jayasingam et al. ${ }^{33}$

The patient counseling domain received a high PRR score next to the teamwork domain. The score was the reflection of pharmacists' engagement with the patients and the ability to counsel about their medication (82.60\%). It also reflects their willingness to spend enough time with patients to discuss about new prescription information (76.91\%) and how to use their medications (76.49\%). Patient counseling in pharmacy is an integral part of pharmacy practice in Malaysia to ensure patient compliance. Pharmacist intervention with patients is directly effective in improving patients' medication adherence and has the potential to improve treatment outcomes. $^{32}$ 
Table 2 Positive response rate (PRR) for individual items and dimensions/composites

Dimensions/items Overall PRR

I. Physical space and environment

73.3

Al. This pharmacy is well organized

87.4

A5. This pharmacy is free of clutter

69.0

A7. The physical layout of this pharmacy supports good workflow

63.4

2. Teamwork

81.0

A2. Staffs treat each other with respect

A4. Staffs in this pharmacy clearly understand their roles and responsibilities

87.6

77.2

A9. Staff work together as an effective team

78.1

3. Staff training and skills

77.6

A3. Technicians in this pharmacy receive the training they need to do their jobs

79.0

A6. Staff in this pharmacy have the skills they need to do their jobs well

79.0

A8. Staff who are new to this pharmacy receive adequate orientation

79.9

A I0. Staff get enough training from this pharmacy

72.6

4. Communication openness

70.2

BI. Staff ideas and suggestions are valued in this pharmacy

55.4

B5. Staff feel comfortable asking questions when they are unsure about something

80.9

BIO. It is easy for staff to speak up to their supervisor/manager about patient safety concerns in this pharmacy

74.3

5. Patient counseling

78.7

B2. We encourage patients to talk to pharmacists about their medications

82.6

B7. Our pharmacists spend enough time talking to patients about how to use their medications 76.5

BII. Our pharmacists tell patients important information about their new prescriptions 76.9

6. Staffing, work pressure, and pace

76.9
46.2

71.4

32.4

49.7

BI2. We have enough staff to handle the workload

31.2

BI6. Interruptions/distractions in this pharmacy (from phone calls, faxes, customers, etc) make it difficult for staff to work

accurately (negatively worded)

7. Communication about prescription across shifts

60.8

B4. We have clear expectations about exchanging important prescription information across shifts 57.6

B6. We have standard procedures for communicating prescription information across shifts 65.0

BI4. The status of problematic prescriptions is well communicated across shifts 59.8

8. Communication about mistakes 65.2

B8. Staff in this pharmacy discuss mistakes 60.7

BI3. When patient safety issues occur in this pharmacy, staff discuss them 60.7

BI5. In this pharmacy, we talk about ways to prevent mistakes from happening again 74.2

9. Responses to mistakes 60.1

$\mathrm{Cl}$. Staff are treated fairly when they make mistakes 71.9

C4. This pharmacy helps staff learn from their mistakes rather than punishing them 71.2

C7. We look at staff actions and the way we do things to understand why mistakes happen in this pharmacy 63.8

C8. Staff feel like their mistakes are held against them (negatively worded) 33.4

10. Organizational learning - continuous improvement 76.6

C2. When a mistake happens, we try to figure out what problems in the work process led to the mistake 81.8

C5. When the same mistake keeps happening, we change the way we do things 80.6

Cl0. Mistakes have led to positive changes in this pharmacy 67.4

II. Overall perceptions of patient safety 51.8

C3. This pharmacy places more emphasis on sales than on patient safety (negatively worded) 36.8

C6. This pharmacy is good at preventing mistakes 51.5

C9. The way we do things in this pharmacy reflects a strong focus on patient safety 66.9

Overall PRR for 36 items

67.0

A higher score in "staff training and skills" reflects the availability of professional training and continuing professional development (CPD) for the practicing pharmacists. The Malaysian Pharmacy Academy provides CPD opportunities for the working pharmacists in support of lifelong learning among pharmacists. For the renewal of an annual retention certificate, each registered pharmacists must have 30 CPD points cumulated in 2 years. The pharmacists are encouraged to attend various training programs conducted by the public and private organizations. The number of training 
Table 3 Comparison between positive response and work experience of pharmacists

\begin{tabular}{|c|c|c|c|c|c|c|}
\hline \multirow[t]{3}{*}{ Items } & \multicolumn{4}{|c|}{ Experience } & \multirow[t]{3}{*}{$\chi^{2}$} & \multirow[t]{3}{*}{ P-value } \\
\hline & \multicolumn{2}{|c|}{$\begin{array}{l}\text { Senior } \\
\text { pharmacist }\end{array}$} & \multicolumn{2}{|c|}{$\begin{array}{l}\text { Junior } \\
\text { pharmacist }\end{array}$} & & \\
\hline & NPR & NOR & NPR & NOR & & \\
\hline Al. This pharmacy is well organized & 98 & 16 & 242 & 34 & 2.7 & 0.22 \\
\hline A5. This pharmacy is free of clutter & 71 & 43 & 173 & 103 & 4.3 & 0.24 \\
\hline A7. The physical layout of this pharmacy supports good workflow & 74 & 40 & 168 & 108 & 3.8 & 0.31 \\
\hline A2. Staffs treat each other with respect & 100 & 14 & 240 & 36 & 3.9 & $0.0 \mathrm{I}^{\mathrm{a}}$ \\
\hline A4. Staffs in this pharmacy clearly understand their roles and responsibilities & 58 & 56 & 206 & 70 & 21.0 & 0.26 \\
\hline A9. Staff work together as an effective team & 83 & 31 & 221 & 55 & 5.1 & $0.02^{\mathrm{a}}$ \\
\hline A3. Technicians in this pharmacy receive the training they need to do their jobs & 83 & 31 & 203 & 73 & 1.6 & 0.27 \\
\hline A6. Staff in this pharmacy have the skills they need to do their jobs well & 86 & 23 & 218 & 58 & 1.2 & 0.33 \\
\hline A8. Staff who are new to this pharmacy receive adequate orientation & 82 & 32 & 220 & 56 & 4.2 & 0.26 \\
\hline BI. Staff ideas and suggestions are valued in this pharmacy & 75 & 39 & 154 & 122 & 6.0 & $0.05^{\mathrm{a}}$ \\
\hline B5. Staff feel comfortable asking questions when they are unsure about something & 94 & 20 & 220 & 56 & 0.9 & 0.54 \\
\hline $\begin{array}{l}\text { BI0. It is easy for staff to speak up to their supervisor/manager about patient safety } \\
\text { concerns in this pharmacy }\end{array}$ & 81 & 33 & 189 & 87 & 0.3 & 0.65 \\
\hline B2. We encourage patients to talk to pharmacists about their medications & 95 & 19 & 222 & 54 & 0.9 & 0.62 \\
\hline $\begin{array}{l}\text { B7. Our pharmacists spend enough time talking to patients about how to use their } \\
\text { medications }\end{array}$ & 92 & 22 & 201 & 75 & 5.3 & 0.37 \\
\hline BII. Our pharmacists tell patients important information about their new prescriptions & 95 & 19 & 202 & 74 & 3.8 & 0.40 \\
\hline B3. Staff take adequate breaks during their shifts & 77 & 37 & 185 & 91 & 0.5 & 0.56 \\
\hline B9. We feel rushed when processing prescriptions & 25 & 89 & 70 & 206 & 0.8 & 0.52 \\
\hline BI2. We have enough staff to handle the workload & 57 & 57 & 128 & 148 & 5.2 & $0.02^{\mathrm{a}}$ \\
\hline $\begin{array}{l}\text { BI6. Interruptions/distractions in this pharmacy (from phone calls, faxes, } \\
\text { customers, etc) make it difficult for staff to work accurately }\end{array}$ & 22 & 92 & 53 & 223 & 0.9 & 0.35 \\
\hline $\begin{array}{l}\text { B4. We have clear expectations about exchanging important prescription } \\
\text { information across shifts }\end{array}$ & 67 & 47 & 134 & 142 & 3.1 & 0.37 \\
\hline $\begin{array}{l}\text { B6. We have standard procedures for communicating prescription information } \\
\text { across shifts }\end{array}$ & 70 & 44 & 145 & $|3|$ & 3.2 & 0.36 \\
\hline BI4. The status of problematic prescriptions is well communicated across shifts & 73 & 41 & 136 & 140 & 3.9 & 0.33 \\
\hline B8. Staff in this pharmacy discuss mistakes & 80 & 34 & 154 & 122 & 4.2 & 0.31 \\
\hline BI3. When patient safety issues occur in this pharmacy, staff discuss them & 78 & 36 & 143 & 133 & 4.1 & $0.02^{\mathrm{a}}$ \\
\hline BI5. In this pharmacy, we talk about ways to prevent mistakes from happening again & 98 & 16 & 196 & 80 & 5.0 & 0.28 \\
\hline $\mathrm{Cl}$. Staff are treated fairly when they make mistakes & 82 & 32 & 188 & 88 & 2.3 & $0.02^{\mathrm{a}}$ \\
\hline C4. This pharmacy helps staff learn from their mistakes rather than punishing them & 91 & 23 & 188 & 88 & 2.9 & 0.41 \\
\hline $\begin{array}{l}\text { C7. We look at staff actions and the way we do things to understand why mistakes } \\
\text { happen in this pharmacy }\end{array}$ & 77 & 37 & 153 & 123 & 3.2 & 0.25 \\
\hline C8. Staff feel like their mistakes are held against them & 13 & 101 & 36 & 240 & 0.9 & 0.59 \\
\hline $\begin{array}{l}\text { C2. When a mistake happens, we try to figure out what problems in the work } \\
\text { process led to the mistake }\end{array}$ & 95 & 19 & 220 & 56 & 2.5 & $0.02^{\mathrm{a}}$ \\
\hline C5. When the same mistake keeps happening, we change the way we do things & 95 & 19 & 212 & 64 & 4.7 & 0.36 \\
\hline Cl0. Mistakes have led to positive changes in this pharmacy & 78 & 36 & 167 & 109 & 1.6 & 0.52 \\
\hline C3. This pharmacy places more emphasis on sales than on patient safety & 23 & 91 & 59 & 217 & 0.9 & 0.36 \\
\hline C6. This pharmacy is good at preventing mistakes & 52 & 62 & 119 & 157 & 2.3 & 0.42 \\
\hline C9. The way we do things in this pharmacy reflects a strong focus on patient safety & 83 & 31 & 164 & 112 & 5.1 & 0.52 \\
\hline
\end{tabular}

Notes: ${ }^{a} P=0.05$; NPR between senior and junior pharmacists were compared.

Abbreviations: NOR, number of other responses; NPR, number of positive responses.

programs on various health-related topics conducted by various organizers are listed in the Malaysian Pharmaceutical society Web site. This may be the reason the practicing pharmacists are responding positively and believe that they have the skills to practice pharmacy effectively.

The environment of the pharmacy is a significant factor related to dispensing errors. Generally, increased dispensing errors were reported where there is an unfavorable working environment. Physical space and environment of the pharmacy are another domain, which scored a higher PRR. A better workplace environment in pharmacies helps the pharmacist to provide better clinical care. The results proved the fact that almost all the pharmacies are adhering to the legal requirements to establish a pharmacy in Malaysia as suggested by the Poison Act 1952. ${ }^{34,35}$ Most of the pharmacies in Malaysia have the highest compliance rate. ${ }^{34}$ 
Table 4 Overall patient safety grade in pharmacy

\begin{tabular}{llll}
\hline $\begin{array}{l}\text { Patient } \\
\text { safety grade }\end{array}$ & $\begin{array}{l}\text { Senior } \\
\text { pharmacist \% }\end{array}$ & $\begin{array}{l}\text { Junior } \\
\text { pharmacist \% }\end{array}$ & Total \% \\
\hline Poor & 0.00 & 1.0 & 1.0 \\
Fair & 1.8 & 7.4 & 9.2 \\
Good & 11.0 & 37.2 & 48.2 \\
Very good & 13.9 & 22.8 & 36.7 \\
Excellent & 2.6 & 2.3 & 4.9 \\
\hline
\end{tabular}

Organizational learning - continuous improvement is another key area, which received a higher PRR score. This result symbolizes a learning culture of practicing pharmacists and encouraging patient safety, continuous learning, and service improvements. ${ }^{36}$

The PRR for "effective communication across shift" showed that there is a need for improvement. Effective communication is very important in dispensing areas to minimize the drug-related problems. It is very essential for staff to discuss about patient safety with their colleagues and learn from each other. In order to enhance the relevance of teamwork, staff must know their own responsibility as well as other team members and engage in discussion on mistakes. ${ }^{37}$ Team members with a high-level understanding are willing to admit their mistakes and accept and appreciate feedback. ${ }^{38,39}$ A mutual understanding between staff members on patient safety issues and a knowledge of probable and possible sources of errors and ways of detecting and avoiding them will promote patient safety. ${ }^{21}$

The PRR for response to mistakes indicates that pharmacists need to focus more on managing dispensing errors. Pharmacists should carry out a root cause analysis in the event of a patient safety incident. This is a retrospective technique for looking for the underlying causes of a patient safety incident behind the immediate and obvious cause. For example, an individual human error might be the immediate cause, but several factors could have contributed to the error, such as fatigue, an inadequate checking system, and poor standard operating procedures. ${ }^{32}$

Only just above the half of the respondents agreed that they emphasize more on patient safety than sales. The results are contrary to a previous study that all three levels of care agreed that the facilities laid greater emphasis on sales than patient safety. ${ }^{21}$ The lowest PRR of a dimension was that of "Staffing, Work Pressure and Pace" (46.18\%), which is similar to that of the studies from People's Republic of China and the USA. ${ }^{22,31}$ The respondents felt that there was not enough staff to handle the workload and they felt rushed processing the prescriptions. The lack of staff members is one of the major contributing factors to medication errors. A study by Nguyen et al reported that high workload, fatigue, and lack of sleep caused medication errors..$^{32}$ The interpretation of the study results indicates respondents' perceptions of inadequacy of staff allocation in handling workload; particularly, interruptions and distractions in a pharmacy. Hence, it is of utmost importance for the adequate allocation of staff members and working hours in an effort to reduce medication errors and thereby enhancing patient safety in retail pharmacies.

The relative frequency or occurrence of patient-related risk events is closely related to the qualification and experience level of pharmacists. ${ }^{40,41}$ There are seven items in our study questionnaire that showed significant difference between the PRR and work experience of pharmacists.

Senior pharmacist scored better, as they know the pitfalls of the pharmacy work and can avoid them masterly, which might reduce the chance of making errors. ${ }^{42}$ The percentage of staff who rated the level of patient safety as "good", "very good", or "excellent" was $89 \%$ in our study, which was higher than the earlier reports by Jia et $\mathrm{al}^{27}$ and lower than the study reported by Norden et al. ${ }^{42}$

The perceived social distance between the patient and the health care practitioner is an important element in patient centeredness. ${ }^{43}$ Ultimately, the pharmacists are accountable for delivering safe pharmaceutical care. However, patients can also play an important role in the reduction of patient safety incidents as there is the opportunity for the patient in avoiding medication errors and their inputs are very much useful in monitoring of adverse events. ${ }^{44,45}$ Patients can communicate with their health professionals if they feel they are vulnerable to any adverse incidents such as risk of medical errors. Patients would like to get more information from the health professionals about such errors and willing to know more about how they can be prevented in the future. ${ }^{46}$ Patients' understanding about their medications is important for the success of the treatment. Their communication with pharmacists or any other health professionals will help them to improve their compliance. ${ }^{47}$

Patient safety in the current Malaysian retail pharmacy setup is satisfactory when compared with other underdeveloped or developing countries..$^{21}$ Furthermore, the pharmacist plays a vital role in maintaining patient safety in considerably good level and exchanging their medication-related information with fellow pharmacists and across the shift to minimize any patient safety issues. Adequate pharmacy staffing and less work pressure and pace give enough time for scrutinizing and delivering prescriptions without any gaffes. The overall 
perception and attitude of pharmacist toward patient safety were agreeable, and further studies are needed to analyze their knowledge of patient safety culture.

These results demonstrated that the PSOPSC can be used to evaluate the effectiveness of patient safety interventions among pharmacists and raise awareness of patient safety culture in the pharmacy setup. The involvement of pharmacists in patient safety will help to improve medication safety and the quality of care. The results also explain the understanding and perceived safety culture and attitudes of community pharmacists in Malaysia. The findings of the study illustrated that pharmacies in Malaysia should have essentials to develop strategies to improve communication about prescription across shifts, responses to mistakes. The improvement in these areas will help them to improve their overall perceptions of patient safety.

\section{Conclusion}

Our results demonstrated that practicing retail pharmacists have a positive attitude and perception toward patient safety, and there was a significant difference in patient safety attitude among senior and junior pharmacists. Their perception toward patient safety was also different from each other. A community of pharmacists with improved perception and positive attitude toward patient safety will reduce the number of medication errors. The results explained the areas of concern to improve safety culture in pharmacy settings, which will be useful in designing training courses for the practicing pharmacist that target specific domains to improve the overall patient safety culture in Malaysian pharmacies.

\section{Acknowledgment}

The authors acknowledge the support provided by the Institute for Research, Development \& Innovation, International Medical University, Malaysia.

\section{Disclosure}

The authors report no conflicts of interest in this work.

\section{References}

1. The Research Priority Setting Working Group of the WHO World Alliance for Patient Safety. Summary of the Evidence on Patient Safety: Implications for Research. Geneva: World Health Organization; 2008.

2. Andermann A, Ginsburg L, Norton P, et al. Core competencies for patient safety research: a cornerstone for global capacity strengthening. Patient Safety Research Training and Education Expert Working Group of WHO Patient Safety. BMJ Qual Saf. 2011;20(1):96-101.

3. Ministry of Health [webpage on the internet]. Guideline on Medication Error Reporting; 2009. Available from: http://www.moh.gov.my/images/ gallery/Garispanduan/Med_Erro/MERS_Guideline_Final.pdf. Accessed April 5, 2016.
4. Cooper JB, Blum RH, Carroll JS, et al. Differences in safety climate among hospital anesthesia departments and the effect of a realistic simulation-based training program. Anesth Analg. 2008;106(2):574-584.

5. Legal Research Board. Malaysian Laws on Poisons and Sale of Drugs. 2014 ed. Malaysia: International Law of Book Services; 2014.

6. Bradley F, Steven A, Ashcroft DM. The role of hidden curriculum in teaching pharmacy students about patient safety. Am J Pharm Educ. 2011;75(7):143.

7. Mansour M. Current assessment of patient safety education. Br J Nur. 2012;21(9):536-543.

8. Pearson PH, Steven A. Patient Safety in Health Care Professional Educational Curricula: Examining the Learning Experience. Report to the National Patient Safety Research Programme. London: Department of Health; 2009.

9. Attree M, CookeH, Wakefield A. Patient safety in an English pre-registration nursing curriculum. Nurse Educ Pract. 2008;8(4):239-248.

10. Pizzi LT, Goldfarb NI, Nash DB. Making Health Care Safer: A Critical Analysis of Patient Safety Practices. Rockville, MD: AHRQ; 2001.

11. Sammer C, James B. Patient safety culture: the nursing unit leader's role. Online J Issues Nurs. 2011;16(3).

12. Zwart DL, Steerneman AH, van Rensen EL, Kalkman CJ, Verheij TJ. Feasibility of centre-based incident reporting in primary healthcare: the SPIEGEL study. BMJ Qual Saf. 2011;20:121-127.

13. Warburton RN. Patient safety-how much is enough? Health Policy. 2005;71(2):223-232.

14. Schutz AL, Counte MA, Meurer S. Development of a patient safety culture measurement tool for ambulatory health care settings: analysis of content validity. Health Care Manag Sci. 2007;10(2):139-149.

15. Kirk S, Parker D, Claridge T, Esmail A, Marshall M. Patient safety culture in primary care: developing a theoretical framework for practical use. Qual Saf Health Care. 2007;16(4):313-320.

16. Colla JB, Bracken AC, Kinney LM, Weeks WB. Measuring patient safety climate: a review of surveys. Qual Saf Health Care. 2005; 14(5):364-366.

17. Sorra J, Famolaro T, Dyer N, Nelson D, Khanna K. Hospital Survey on Patient Safety Culture 2008 Comparative Database Report. Rockville, MD: Agency for Healthcare Research and Quality; 2008. [Prepared by Westat, Rockville, MD, under contract No 233-02-0087, Task Order 18]. AHRQ Publication No 08-0039.

18. Rajiah K, Maharajan MK, Nair S. Pharmacy students' knowledge and perceptions about adverse drug reactions reporting and pharmacovigilance. Saudi Pharm J. In press 2015.

19. Malaysian Adverse Drug Reactions Advisory Committee [webpage on the Internet]. National pharmaceutical control bureau. [about NPCB]. Available from: http://bpfk.moh.gov.my/index.php/aboutnpcb/malaysian-adverse-drug-reactions-advisory-committee-madrac/ introduction. Accessed May 20, 2016.

20. Westat R, Martha F, Joann S [webpage on the Internet]. Pharmacy survey on patient safety culture: User's Guide. Agency for healthcare quality and research. US department of health and human services; 2012. Available from: http://www.ahrq.gov/professionals/qualitypatient-safety/patientsafetyculture/pharmacy/index.html. Accessed March 7, 2016.

21. Bao NJ, Shao H, Nie XY, et al. Analysis of the status of clinical pharmacist pilot training in Chinese hospitals. Chin Pharm Sci. 2011;20(4): 410-414.

22. Henson RK. Understanding internal consistency reliability estimates: a conceptual primer on coefficient alpha. Measure Eval Counsel Develop. 2001;34(3):177-189.

23. Westat R [webpage on the Internet]. Preliminary comparative results: pharmacy survey on patient safety culture. Department of Health and Human Services, 2012. AHRQ Publication No 12-0085-1-EF: U.S. Available from: http://www.ahrq.gov/sites/default/files/wysiwyg/professionals/quality-patient-safety/patientsafetyculture/pharmacy/2012/ PharmSOPS_PilotResults.pdf. Accessed March 30, 2016.

24. Said B, Emel F. A survey on patient safety culture in primary healthcare services in Turkey. Int J Qual Health Care. 2009;21(5):348-355. 
25. Nie YL, Mao XY, Cui H, He S, Li J, Zhang M. Hospital survey on patient safety culture in China. BMC Health Serv Res. 2013;13:228.

26. Chen IC, Li HH. Measuring patient safety culture in Taiwan using the hospital survey on patient safety culture (HSOPSC). BMC Health Serv Res. 2010;10:152.

27. Jia PL, Zhang LH, Zhang MM, et al. Safety culture in a pharmacy setting using a pharmacy survey on patient safety culture: a cross-sectional study in China. BMJ Open. 2014;4(6):e004904.

28. Hellings J, Schrooten W, Klazinga N, Vleugels A. Challenging patient safety culture: survey results. Int $J$ Health Care Qual Assur. 2007; 20(7):620-632.

29. Bodur S, Filiz EA. survey on patient safety culture in primary healthcare services in Turkey. Int J Qual Health Care. 2009;21(5):348-355.

30. Norden HA, Sexton JB, Kalvemark SS, Ring L, Kettis LA. Assessing safety culture in pharmacies: the psychometric validation of the Safety Attitudes Questionnaire (SAQ) in a national sample of community pharmacies in Sweden. BMC Clin Pharmacol. 2010;10:8.

31. Joann S, Theresa F, Naomi DY, Scott AS, Stephen W, Helen L. 2014 User Comparative Database Report: Hospital Survey on Patient Safety Culture. Rockville, MD: Agency for Healthcare Research and Quality, Westat; 2014.

32. Nguyen EE, Connolly PM, Wong V. Medication safety initiative in reducing medication errors. J Nurs Care Qual. 2010;25(3):224-230.

33. Jayasingam $S$, Ansari MA, Jantan M. Influencing knowledge workers: the power of top management. Indus Manag Data Sys. 2010;110(1): 134-151.

34. Eniojukan JF, Okinedo PO, Ishiekwene AK, Aghoja OC. Comparative evaluation of pharmacy patient safety culture in all levels of health care delivery in Delta State, Nigeria. UK J Pharm Biosci. 2015;3(5): 30-40.

35. Palanisamy S, Sumathy A. Intervention to improve patient adherence with antihypertensive medications at a tertiary care teaching hospital. Int J PharmTech Res. 2009;1(2):369-374.
36. David PB, Rachel D, Eduardo S. Teamwork as an essential component of high-reliability organizations. Health Serv Res. 2006;41(4 Pt 2): 1576-1598.

37. Bandow D. Time to create sound teamwork. J Qual Part. 2001;24(2): 41-47.

38. Webber SS. Leadership and trust facilitating cross-functional team success. J Manag Develop. 2002;21(3):201-214.

39. Siang CS, Kee WW, Gee LH, Richard Y, Hui JTS. Implementation of the benchmarking guidelines on community pharmacies in Malaysia. Malaysian J Pharm Sci. 2008;6(1):13-31.

40. Martin A. Professional Standards for Hospital Pharmacy ServicesOptimising Patient Outcomes from Medicines. 2nd ed. London: Royal Pharmaceutical Society; 2014.

41. General Pharmaceutical Council [webpage on the Internet]. Responding to Complaints and Concerns; 2010. Available from: https://www. pharmacyregulation.org/sites/default/files/Responding $\% 20$ to $\% 20$ complaints\%20and\%20concerns\%20g.pdf. Accessed March 6, 2016.

42. Norden HA, Kalvemark SS, Lindblad AK. Exploring the relationship between safety culture and reported dispensing errors in a large sample of Swedish community pharmacies. BMC Pharmacol Toxicol. 2012;13:4

43. Hovey RB, Dvorak ML, Burton T, et al. Patient safety: a consumer's perspective. Qual Health Res. 2011;21(5):662-672.

44. Koutantji M, Davis R, Vincent C, Coulter A. The patient's role in patient safety: engaging patients, their representatives, and health professionals Clin Risk. 2005;11:99-104.

45. Vincent C, Coulter A. Patient safety: what about the patient? Qual Saf Health Care. 2002;11(1):76-80.

46. Gallagher TH, Waterman AD, Ebers AG, Faser VJ, Levinson W. Patients' and physicians' attitude regarding the disclosure of medical errors. J Am Med Assoc. 2003;289(8):1001-1007.

47. Maxwell S. Rational prescribing: the principles of drug selection. Clin Med. 2009;9(5):481-485.
Patient Preference and Adherence

\section{Publish your work in this journal}

Patient Preference and Adherence is an international, peer-reviewed, open access journal that focuses on the growing importance of patient preference and adherence throughout the therapeutic continuum. Patient satisfaction, acceptability, quality of life, compliance, persistence and their role in developing new therapeutic modalities and compounds to optimize

\section{Dovepress}

clinical outcomes for existing disease states are major areas of interest for the journal. This journal has been accepted for indexing on PubMed Central. The manuscript management system is completely online and includes a very quick and fair peer-review system, which is all easy to use. Visit http://www. dovepress.com/testimonials.php to read real quotes from published authors. 